\title{
Jornais e revistas de teatro em Portugal
}

\section{Luiz Francisco Rebello}
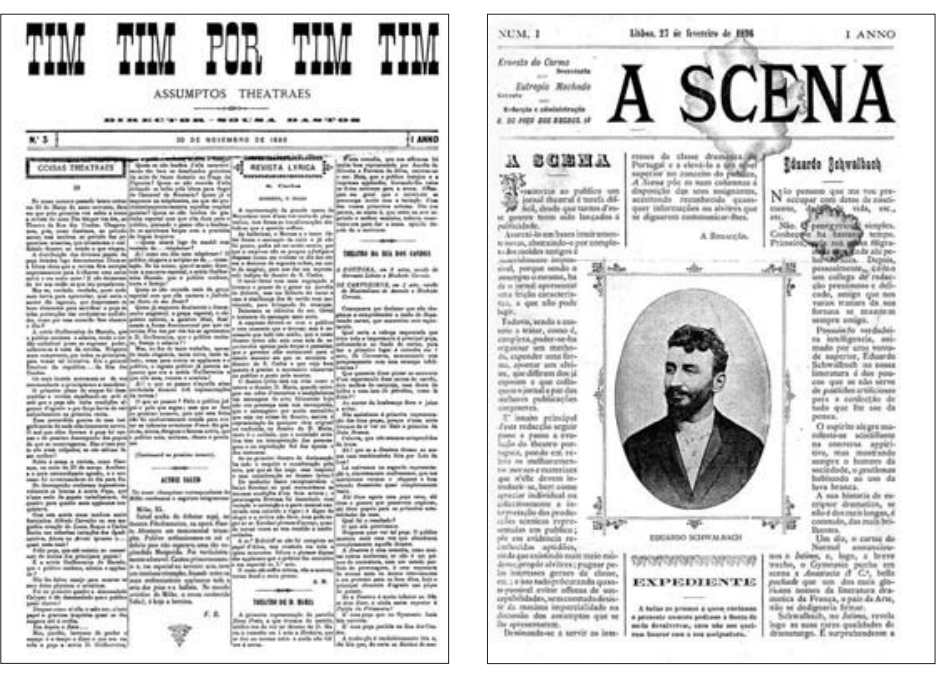

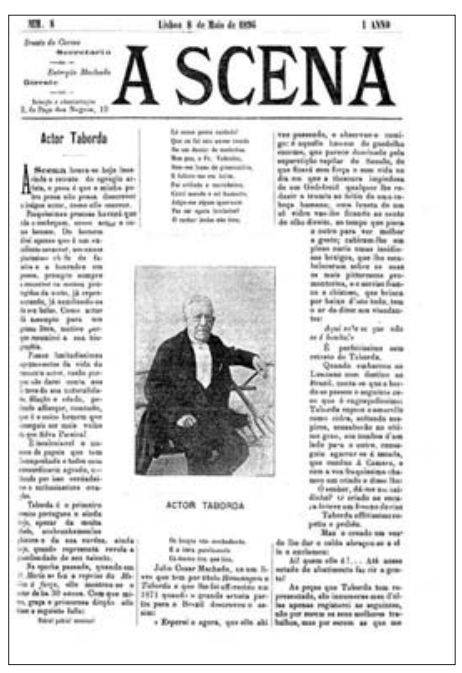

Num texto recente, de grande abrangência, sobre a dramaturgia portuguesa no século XX, Maria Helena Serôdio deixou registado que "são raríssimas e irregulares as revistas de teatro em Portugal" (2004: 99), e é justa a observação sobretudo no que aos tempos mais próximos diz respeito. Mas não foi sempre assim.

Historicamente, o primeiro jornal de língua portuguesa de que há notícia terá sido a "Gazeta em que se relatam as novas todas que houve nesta corte, e que vieram de várias partes, no mês de Novembro de 1641", que até Setembro de 1647 continuaria a publicar-se mensalmente - mas as notícias, de sucessos nossos ou alheios, que divulgava eram de natureza exclusivamente política e militar. Seria preciso que decorresse mais de um século até aparecer uma publicação periódica em que era concedido espaço à actividade teatral: a Gazeta Literária, do Padre Francisco Bernardo de Lima, que no Porto se imprimiu e teve a duração de um ano (Julho de 1761 a Julho de 1762). Propunha-se o seu redactor dar "notícia exacta dos principais escritos que modernamente se vão publicando na Europa, conforme a análise que deles fazem os melhores críticos e diaristas das nações mais civilizadas" - e a literatura dramática, esporadicamente embora, não foi esquecida.

Mas é no século XIX, sobretudo após o advento do liberalismo, que se assiste a uma verdadeira explosão da imprensa periódica (entre 1820 e 1823 surgem trinta novos jornais por ano, média que sobe para mais do dobro em 1836), com destaque para a imprensa especializada. Em 1813 sai o primeiro número do Teatro Nacional, que inseria os anúncios dos espectáculos levados à cena no Teatro da rua dos Condes; em 1825, no Porto, o Boletim Teatral; em 1835 um Jornal de Comédias e Variedades. No ano seguinte, Garrett empreende a grande reforma do teatro português
- a mais profunda e consequente da sua história -, de que um dos pilares era a criação de um Conservatório para "fomentar a Arte Dramática, e suas subsidiárias, tão abandonadas e perdidas entre nós", lê-se no $§ 5 .^{\circ}$ do artigo 3. da histórica portaria de 15 de Novembro. Em defesa das suas ideias - e do seu projecto global - o futuro autor de Frei Luis de Sousa fundou, em 1837, um jornal, Entreacto, que dirigiu (e redigiu) com o pseudónimo João Vaz, de que se publicaram vinte números entre 17 de Maio e 2 de Julho; o mesmo título seria utilizado em 1840, 1852, 1883 e, no Porto, 1879, por outras tantas publicações noticiosas, todas elas de escassa duração. Para Garrett, tratava-se de "conversar amiúde com o público sobre os seus divertimentos e moralizar sobre eles". 0 Entreacto de 1840, porém, destinava-se praticamente a defender uma jovem cantora de ópera contra os ataques desferidos pelos adeptos de uma sua rival noutra publicação...

Começou o Conservatório a funcionar no último trimestre de 1839, e logo uma revista teve início de publicação "para sustentar o pensamento da restauração da arte dramática em Portugal", o Jornal do Conservatório, que viria a ter continuidade, com o título alterado para Revista do Conservatório Real de Lisboa, em 1842, e, entrado já um novo século, reapareceria com esta designação, então sob a direcção do dramaturgo Eduardo Schwalbach.

Mas entretanto outras revistas foram surgindo, e logo duas em 1838, com relevância para a vida teatral da época, apesar de a sua existência haver sido breve: A Atalaia Nacional dos Teatros, de Junho a Agosto, O Desenjoativo Teatral, de Julho a Setembro, dirigida aquela por Luis Baiardo, este por Rodrigo da Câmara, autores dramáticos ambos. Uma razão polémica estava na origem do seu nascimento. Enquanto se arrastavam as diligências para a construção 
do Teatro Nacional para ai se "poderem decentemente representar os dramas nacionais" (e haveria que esperar ainda até 1846 !), Garrett erigia o velho Teatro da rua dos Condes, "uma espelunca imunda e carunchosa" no dizer do dramaturgo Costa Cascais, à categoria de Teatro Nacional e Normal e organizava uma companhia com os principais actores do seu tempo, confiando a direcção ao actor e encenador - a palavra não existia nessa data - Émile Doux. Do seu lado, Castilho, com o apoio de Herculano, fundava a Associação Gil Vicente e formava uma outra companhia para actuar no Teatro do Salitre, crismado de Real Teatro Português, que não desmerecia no confronto com aquele: "uma baiuca", assim o definiu Anselmo Braancamp. A Atalaia terçava armas pelo Condes, 0 Desenjoativo pelo Salitre. E nesse despique consumiam as suas páginas...

Não diferem muito desse modelo as várias dezenas de revistas publicadas até ao fim do século, e deste até à implantação da ditadura emergente do golpe militar de 1926 e a consequente sujeição da imprensa à censura prévia. Para além da informação factual sobre os espectáculos em cena, o que avulta são as querelas de bastidores, as anedotas de camarim (e, subliminarmente, por vezes de cama...). Quase todas têm Lisboa por berço, mas eventualmente 0 Porto ou Coimbra, como neste último caso, a Crónica Teatral da Nova Academia Dramática, de 1839, ano que viu também nascer O Elenco, O Recreio Teatral, uma Galeria Teatral e uma Revista Teatral, a que sucederia no ano seguinte A Sentinela do Palco, na mesma linha, e com a mesma finalidade, da Atalaia de 39. De 1842 é O Espelho do Palco, e são nada menos de seis as que saem dos prelos em 43: A Ulisseia Dramática, O Espectador (com o mesmo título se publicaria um "jornal dos teatros e das filarmónicas"), O Neorama Teatral, O Raio Teatral, a Resenha Teatral e uma segunda Revista Teatral dirigida por Mendes Leal, o autor do famoso drama ultra-romântico Os dois renegados.

Sem a pretensão de apresentar aqui um inventário exaustivo, mencionem-se, todavia, 0 Correio dos Teatros,
O Eco dos Teatros e O Relâmpago (1845); a Revista dos Espectáculos, suplemento de um jornal que depois se autonomizou (1850-59); a Crónica dos Teatros, em que colaboraram Camilo, Teófilo Braga, Júlio César Machado, Biester, Joaquim de Vasconcelos e o "mimoso poeta Vidal", entre muitos outros (1861-71); o semanário O Espectador Imparcial (1868); A Arte Teatral, que tinha como redactor principal o empresário e autor Sousa Bastos e se dizia "folha instrutiva, crítica e noticiosa" (1873-78); O Contemporâneo, dedicado às "letras, artes, ciências, livros, palcos, quadros e salas", com colaboração de Gervásio Lobato, Salvador Marques, Pedro Vidoeira (1875-82); a folha quinzenal de crítica teatral A Plateia (1875-76); O Mundo Artístico, jornal ilustrado de música, teatro e belas-artes, dirigido por Monteiro de Carvalho (1883); Tim Tim por Tim (1), revista de assuntos teatrais dirigida por Sousa Bastos para promoção dos seus espectáculos, de incómodo formato $(30 \times 44 \mathrm{~cm})$, em que se publicou o texto integral da revista Fim de Século (188993); A Ribalta, semanário dedicado aos amadores dramáticos (1893), dirigida por José Garcia de Lima, que reincidiria em 1896 com A Scena (2, 3 e 4); Palcos \& Circos (1894); a revista quinzenal de música, teatro e belas-artes Amphion (1897); 0 Crítico, órgão dos teatros em geral e dos amadores dramáticos em especial, sob a direcção de João Borges (1898) - sem esquecer 0 Almanaque dos Palcos e Salas, que teve longa vida pois se publicou regularmente entre 1889 e 1928.

Em medida muito diversa, todos estes jornais e revistas contêm material interessante para o conhecimento prático da história (e da pequena história) do espectáculo teatral entre nós e do meio sócio-cultural em que se inscreve. Mas não vão além disso, e com frequência ficam aquém. Uma excepção importa, no entanto, ressalvar: a Revista Teatral, dirigida por Joaquim Miranda e Colares Pereira, de que uma primeira série (dezanove números) se publicou quinzenalmente de Janeiro a Setembro de 1885 e a segunda (quarenta e oito números) de Janeiro de 1895 a Dezembro do ano seguinte (5). 0 nível crítico e literário deste periódico
(4) (5) (6) >

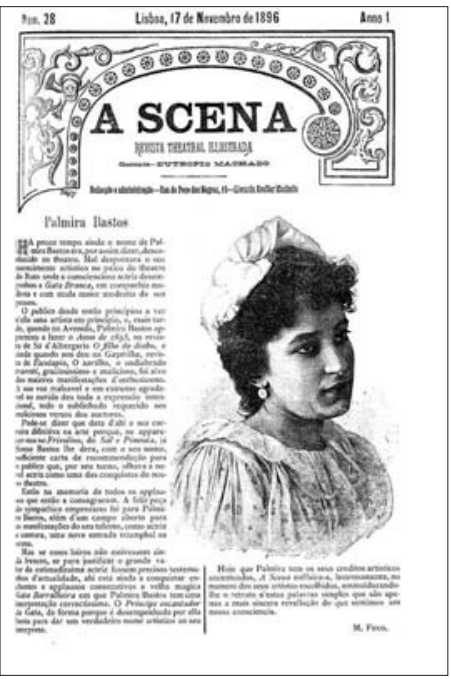

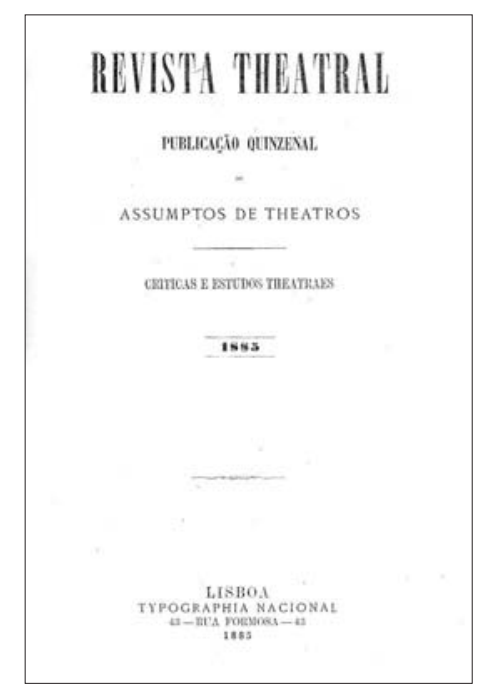

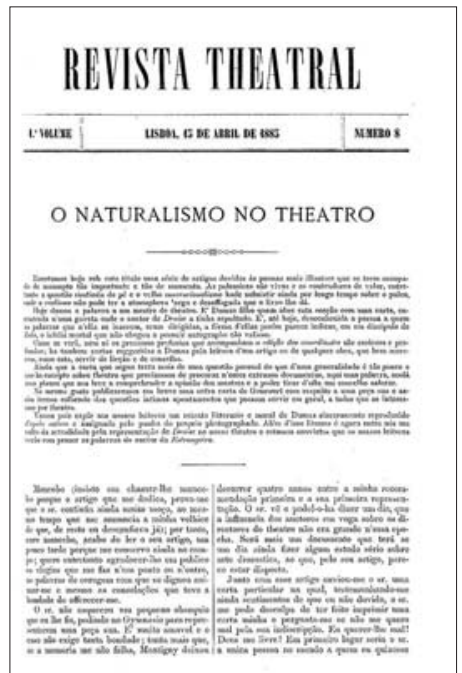


de "críticas e estudos teatrais" sobreleva, em muito, o de quantas a precederam, e até de muitas que lhe sucederam.

Só por si, justificaria ela que se Ihe dedicasse um artigo próprio, tanto é - descontadas, evidentemente, as limitações da época - o material que nos transmite sobre o pensamento crítico num país em que (e cito um opúsculo de Carl Bush, editado em 1870, Da crítica teatral em Portugal) "coisa que toda a gente sabe e ninguém quer confessar, é que não existe critica teatral".

Corroborando este juizo, os directores da Revista Teatral lamentariam, num texto inicial, "a ausência completa de crítica no nosso teatro", "sacrificada a delicadezas particulares, a interesses pessoais ou a tricas dos bastidores"...

Propunha-se a Revista suprir essa lacuna incluindo nas suas páginas um comentário desenvolvido sobre os espectáculos em cena (e nos palcos doutros países, com destaque para a França), detendo-se particularmente no argumento das peças e na sua estrutura externa (agenciamento da acção e das situações, desenho e comportamento das personagens) - com o acréscimo de textos de investigação ou simples informação histórica e de referência à evolução da arte dramática. Entre os primeiros, além de uma secção de "efemérides teatrais", merecem realce os estudos de Teófilo Braga e Henrique Lopes de Mendonça, aquele sobre as origens do teatro português e a fundação do teatro nacional, este sobre o Pátio das Arcas; a série de artigos de Charles Magnin e Licínio de Carvalho sobre as origens do teatro antigo e da arte dramática; os artigos relativos ao teatro na China e no Japão - e, entre os segundos, os textos de Dumas filho, Edmond de Goncourt e Zola acerca do "Naturalismo no teatro" (6) e de Pinheiro Chagas sobre a recepção do teatro escandinavo em França (Ibsen e Bjornson foram, aliás, objecto de artigos individuais). E foi nas suas páginas que Fialho de Almeida publicou o seu, depois tão divulgado, estudo sobre o teatro de revista, Augusto de Lacerda dissertou sobre a mise-en-scène, e pela primeira vez se traduziu o Paradoxo sobre o comediante, de Diderot, cento e vinte anos depois de ele o haver escrito...

Curiosamente a Revista recolheu também nas suas páginas excertos de obras dramáticas, como Aspásia, peça de estreia de Augusto de Lacerda, A pérola, de Marcelino Mesquita, A toutinegra real, de D. João da Câmara, o Fausto, de Goethe na tradução de Castilho, Otelo e Romeu e Julieta, de François Coppé, e Mancha que Limpia, de Echegaray. E não deve menosprezar-se a energia com que se bateu pela independência e a dignidade do teatro português, dos autores portugueses, dos actores portugueses, colocandose acima das questiúnculas que os aviltavam e dividiam.

Por isso, no seu derradeiro número, ao anunciarem o seu fim, os directores puderam escrever que a sua revista "era hoje uma planta exótica no meio em que vivia" - e "morria como nasceu, intransigente e desapaixonada, honesta e escrupulosa, cônscia da sua missão e cumpridora do seu dever".

Agonizava o século XIX. Veremos, no próximo artigo, como esta situação evoluiu no que iria suceder-lhe.

\section{Referências bibliográficas}

SERÔDIO, Maria Helena (2004), "Dramaturgia", in Fernando J.B. Martinho (coord.), Literatura portuguesa do século XX, Lisboa, Instituto Camões, pp. 95-141.

PEREIRA, Silva (1895-96), "Os primeiros jornais de teatro de Lisboa", Revisto Teatral, Lisboa, n. 23 , pp. 354-355; n. 25 , pp. 15-16; n. 26, pp. $31-$ 32; n. 28 , pp. 63-64; n. 29 , pp. 87-88; n. ${ }^{\circ} 35$, pp. 184-186; n. 36 , pp. 198-199.

SAMPAIO, Albino Forjaz de (1924), "Revistas de Teatro", De Teatro, n. 22, Julho, p. III. 